\title{
THE TORTUGAS LABORATORY
}

\author{
By PRof. K. M. Yonge, \\ University of Bristol
}

$\mathrm{N}$ EWS has recently been received that the Marine Biological Laboratory of the Carnegie Institution of Washington at the Tortugas Keys, Florida, has been closed owing to necessary restrictions of the Institution's programme in certain directions. The Laboratory buildings have been handed over to the United States Government, that portion of Loggerhead Key on which they stand having been originally leased from the Government for purposes of marine biological research.

The passing of this Laboratory, for thirty-six years one of the few centres of biological research in tropical waters, demands some words of farewell. Its origin is intimately connected with the history of zoology in the United States. Louis Agassiz visited the Tortugas Keys in 1851 in the course of his survey of the Florida reefs, and Alexander Agassiz spent some weeks upon them in 1881. His admirably illustrated report was published two years later in the Memoirs of the American Academy of Arts and Science. There is reproduced in "The Letters and Recollections of Alexander Agassiz" by G. R. Agassiz, a letter to Charles Darwin, headed Tortugas, April 16, 1881, in which Agassiz writes of his activities in mapping out the distribution of the corals.

Recollections of this visit must have been uppermost in his mind when Agassiz, in his capacity as a trustee of the recently founded Carnegie Institution of Washington, pressed for the addition of a Department of Marine Biology to its many activities. But he did more than suggest the site for the Laboratory: he provided, in the person of one of his former scientific assistants, Dr. A. G. Mayor, a director who was to control its activities with outstanding success from its inception in 1904 until his untimely death of 1922. It is impossible to think of the Tortugas Laboratory apart from Mayor. His greatest work was done at the Laboratory or on the numerous marine expeditions to the Bahamas and other islands of the West Indies, to Murray Island, Fiji and Samoa, financed by the Department of Marine Biology. His fundamental contributions to the study of Cœlenterates and Ctenophores were largely carried out at the Tortugas.

The wooden laboratory and living rooms were erected near the western extremity of the long sandy island of Loggerhead Key in the summer of 1904. A photograph reproduced in the third
Year Book of the Carnegie Institution shows them as they were originally erected, on the bare sand fully exposed to the glaring sun. Visitors in later years were impressed with the wealth of vegetation which surrounded and shaded the buildings. But the coco-nut palms and ironwood trees were planted by Mayor to provide shade and some protection from hurricanes which may sweep with devastating force over this portion of the Gulf of Mexico during the autumn. With the passage of years additional buildings were added, while the capacious M.V. Anton Dohrn replaced the auxiliary ketch $P$ hysalia.

The reefs of the Tortugas form a rough circle, there being the usual sharp descent into deep water on the north-eastern, that is, weather, side. Here the force of the sea driven by the trade winds is too great to permit the formation of a sand key, but shingle ramparts of coral fragments have formed on the inner side of the reef, and in the shelter of these a few mangrove trees find precarious existence. Loggerhead Key lies on the south-west, in the lee of the reef complex, and its shores are buttressed by beach limestone. Other sand keys are scattered about, notably Long Key, which is relatively densely vegetated and provides a nesting place in the summer for hosts of sooty terns and noddies, as well as for the majestic frigate birds which batten on these smaller birds. The entire reef complex was, to me, vividly reminiscent of conditions on the reefs of the Great Barrier of Australia, which are moulded by the action of the south-east trades.

A unique feature is provided by the Marquesas Keys, which lie between the Tortugas and Key West and form an almost perfect ring. They contain no living coral but are formed of calcareous material of mixed origin thrown up above the surface and moulded by the action of the prevailing winds and currents.

The most remarkable feature of the Tortugas Keys is undoubtedly the immense brick erection of Fort Jefferson, which entirely covers one of the sand keys. Successive parties of visiting zoologists used to calculate the millions of bricks which had gone to its construction and the extent of the labour involved in their transport from Key West, seventy miles away. The military value of the Fort appeared problematical, but of its biological value there was, surprisingly, no question. On the piles of the wharf, in the deep shade cast by the crumbling planking overhead, grew corals 


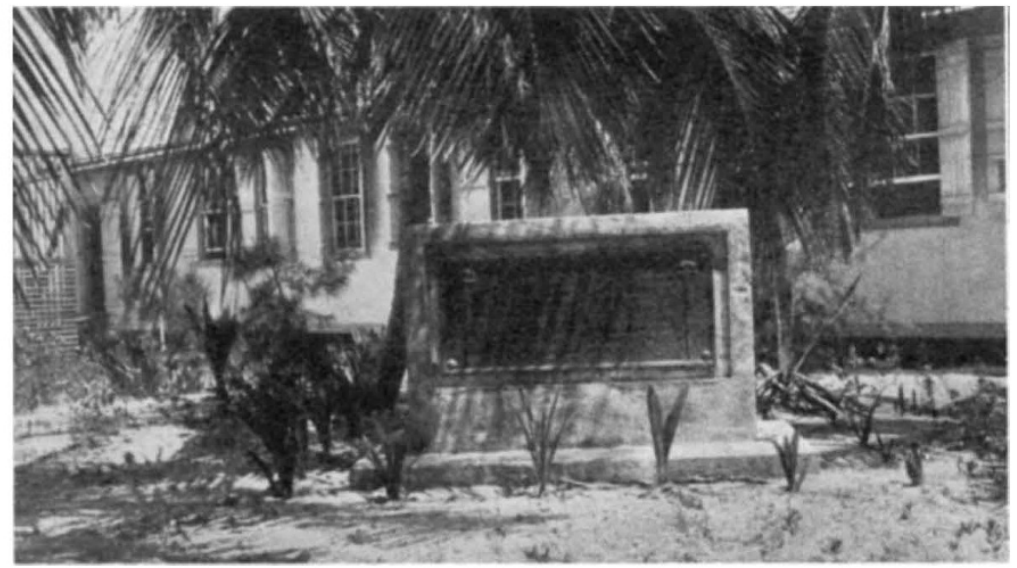

Fig. 1.

Memoriat to Dr. A. G. Mayor at loggerhead Key, Tortugas. The LABORATORY HUT IS SEEN BEHIND.

otherwise obtainable only in relatively deep water. Within the still waters of the wide moat there flourished, within easy access in all weathers, a representative collection of shallow-water corals and other organisms such as Cassiopea xamachana, on which much of Mayor's experimental work on Scyphozoa was conducted. During the great hurricane of 1919 the moat, which had stood undamaged for some seventy years, was breached on the north-western side, and further damage was suffered later. The result was to interrupt the previous flow of water through the moat so that those portions which remained filled constituted a sediment trap. A large-scale experiment in Nature was thus provided. A full list of the corals originally present had been provided by Vaughan in 1918 and they included all species typical of the inner reef flat. But when I examined the moat in 1934, apart from a few stunted specimens of other corals, the only common species was Siderastrea radians, which exhibited exceptional powers of modification, permitting life both in the surf region and also in still, sediment-laden waters.

It is natural first to consider corals in an account of the work of the Tortugas Laboratory. It was with these organisms and with the reefs which they form that Mayor and his principal associates, T. Wayland Vaughan, L. R. Cary and F. A. Potts among others, were primarily concerned. But the yearly visitors to the Laboratory covered a wide field in marine biology, as will quickly be revealed by reference to the con- tents of the well-known Papers from the Tortugas Laboratory, the thirty-second volume of which is now in course of publication. Mention of the work of W. B. Setchell on marine algæ, of A. L. Treadwell on annelids, of W. $\mathrm{H}$. Longley on fishes, of $\mathrm{D}$. $\mathrm{H}$. Tennant and H. Lyman Clark on echinoderms and of P. Bartsch on molluses, must suffice to indicate the range and value of this work.

After the death of Mayor in 1922 the Carnegie Institution did not appoint a new director, but Dr. W. H. Longley, of Goucher College, Baltimore, acted as executive officer in charge until his death in 1937, after which Dr. D. H. Tennant, of Bryn Mawr College, continued in the same capacity.

The Carnegie Institution has been most generous in its hospitality and many British workers have enjoyed the unique facilities of the Tortugas Laboratory. It was an exclusively male community, so that activities were never curtailed by any respect for the conventions of dress. One of the larger huts constituted a dormitory which contained a line of hammocks draped with mosquito netting. In the same hut were lodged the library and a laboratory, but a second, more recent, hut contained the principal laboratory and a working aquarium. Two motor-boats kept workers supplied with material, while the Anton Dohrn made occasional visits farther afield, as well as regular runs to Key West for stores and mail. The ingenuity and skill of Captain John Mills, engineer and seaman of unfailing energy and high spirits,

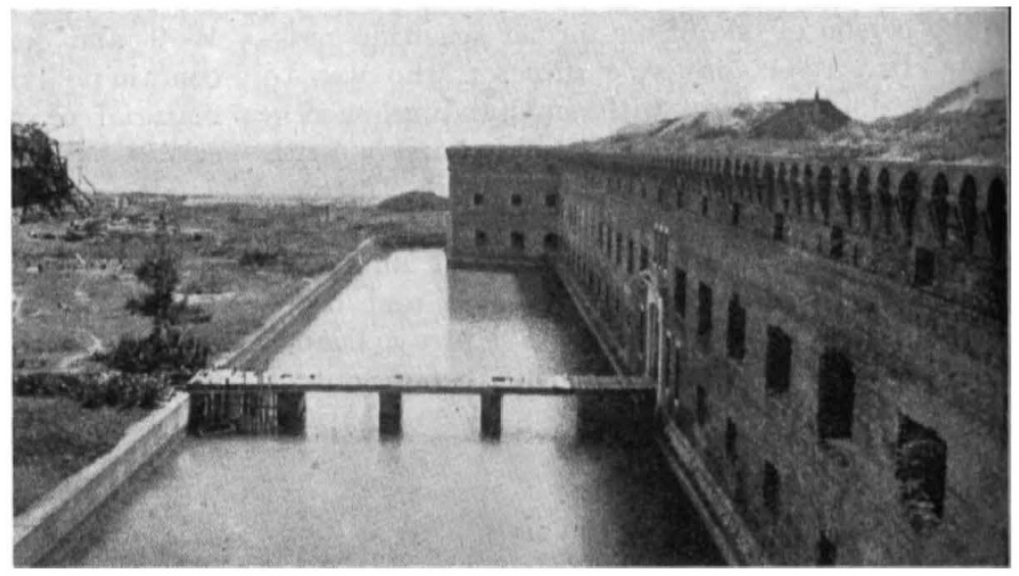

Fig. 2 .

Fort Jefferson, Tortugas, showing a portion of the moat and the BRIDGE LEADING TO THE MAIN ENTRANCE. 
never failed to provide an answer to all problems of material and experimental equipment.

But for the War of 1914-18 it is possible that the Laboratory might, as Mayor wished, have been transferred to Montago Bay, Jamaica. Direct co-operation would thus have been possible between marine biologists from the United States and Great Britain. One can but hope that this aspect of the manifold activities of the Carnegie Institution of Washington may be resumed in due course, perhaps in collaboration with the Bermuda Biological Station.

\section{CORROSION OF IRON AND STEEL IN SEA WATER*}

$\mathrm{T}$ $\mathrm{HE}$ eighteenth report of the Committee of the Institution of Civil Engineers on the Deterioration of Structures of Timber, Metal and Concrete exposed to the Action of Sea Water contains the final results of the fifteen years exposure of iron and steel specimens in the four harbours named, and also summarizes the results, previously published, of the five- and ten-year series. The observations on ferrous specimens are therefore now complete. Although the total number of bars exposed was large, only three of each material were exposed in each position, one of the three being removed at the end of each five-year period, so that there were no actual duplicates. It follows that accidental differences have a rather large effect, and it is only possible to make roughly quantitative comparisons, best expressed in graphical form. Naturally, wide differences were found between the results at different stations, partly on account of the prevailing temperature, but also owing to local circumstances. Thus, at Colombo the rise and fall of the tide is small, so that the half-tide specimens, being for most of their time in contact with water, were more nearly comparable with completely immersed specimens at other stations, and the bars exposed to the air were so often wetted by spray as to be comparable with half-tide specimens elsewhere.

All bars in this series of experiments were unpainted, but several materials were tested in two conditions: with adherent rolling scale and after removal of scale. The scale affords only temporary protection, and when flaking begins deep pits may be formed; so that although a scale-bearing bar may show a smaller loss of weight than its companion with the scale removed, it may actually be in a worse condition. Complications also arise from the accumulation of marine growths. In some instances this has led to a falling off of the rate of corrosion in the last five years of the test, the adherent growth being protective. On the other

- Deterioration of Structures of Timber, Metal and Concrete Exposed to the Action of Sea-Water. Eighteenth Report of the Committee of the Institution of Civil Engineers: Being a General Discussion of the Results of the Corrosion Tests carried out with Ferrous Specimens for 5, 10 and 15 Years at Auckland (New Zealand) Colombo (Ceylon), Halifax (Canada) and Plymouth (England). By Dr, J. Newton Friend. Edited by H. J. Grose. Pp. iv $+52+9$ plates, Ltd., 1940.) 88. 6d. hand, considerable pitting may be found under the marine organisms.

Considering the materials in detail, cast iron behaved well in air, but when submerged was very liable to 'graphitization', the outer form being retained but the interior being converted into a spongy mass without strength. High-alloy steels of the austenitic type showed, as might be expected, a much higher resistance than carbon or low-alloy steels, but the cutlery type of stainless steel was less satisfactory when immersed in sea water. Such materials, from their high cost, can only be used in exceptional circumstances. Of the low alloy steels, those containing copper behaved well when exposed to air, but less well in sea water.

For practical purposes, mild steel and wrought iron are the most important ferrous materials, and it is this section of the report which will, receive most attention. Using a system of averaging the results which was adopted after consideration, the numbers being too small for statistical treatment, it appears that under aerial conditions mild steel is less corroded than wrought iron of high quality ; in fresh water there is little difference; and in sea water the wrought iron has the advantage. Some remarks on the effect of impurities in steel call for comment. The steel with high sulphur was also high in phosphorus, and the discussion seems to imply that the influence of these two elements would be in the same direction, which is unlikely. There were no specimens in which sulphur and phosphorus were varied independently.

On the whole, the results of these extensive field tests, carried out over a long period and with careful planning, are very much what might have been expected. The work of the Committee has, of course, covered much more ground than that of the present report, as it included both timber and concrete structures, as to the resistance of which to marine conditions there was much less information available. Of iron and steel it may be said that the inherent resistance of the ordinary varieties to marine corrosion does not vary very widely and that some form of protection is nearly always essential. Much more work on the nature of the corrosive process is needed, and is now actively in progress.
C. H. D. 